\title{
Single Stage PFC Flyback AC-DC Converter Design
}

\author{
Kali Naraharisetti, Member, IEEE, Janamejaya Channegowda, Member, IEEE,
}

\begin{abstract}
This paper discusses a $100 \mathrm{~W}$ single stage Power Factor Correction (PFC) flyback converter operating in boundary mode constant ON time methodology using a synchronous MOSFET rectifier on the secondary side to achieve higher efficiency. Unlike conventional designs which use two stage approach such as PFC plus a LLC resonant stage or a two stage PFC plus flyback, the proposed design integrates the PFC and constant voltage regulation in a single stage without compromising the efficiency of the converter. The proposed design is advantageous as it has a lower component count. A design of $100 \mathrm{~W}$ flyback operating from universal input $\mathrm{AC}$ line voltage is demonstrated in this paper. The experimental results show that the power factor (PF) is greater than 0.92 and total harmonic distortion (iTHD) is less than $20 \%$ for a load varying from $25 \%$ to $100 \%$. The experimental results show the advantages of a single stage design.
\end{abstract}

Keywords - Critical Conduction Mode (CrCM), Power Factor Correction (PFC), Total harmonic distortion (iTHD), Flyback converter

\section{INTRODUCTION}

All power supplies in the market with a power rating greater than $75 \mathrm{~W}$ have to comply with an international regulation standard IEC 61000-3-2 [1]. This standard puts a limitation on the current harmonic percentage for class $\mathrm{D}$ power supplies in the power range of $75 \mathrm{~W}$ to $600 \mathrm{~W}$ [2], [3]. Power supplies and power adapters less than $75 \mathrm{~W}$ do not have a requirement on the total harmonic distortion (iTHD) or power factor correction (PFC).

A power supply which does not have a PFC front end stage draws the input current only when the diode rectified voltage is greater than the DC link capacitor voltage [4]. The pulsating input current will have higher amounts of harmonics which translates to power loss within the converter. In other words, the power converter is drawing current more than required. In low power LED applications (less than $50 \mathrm{~W}$ ), a single stage boundary mode PFC flyback converter is commonly used because of low cost, wide input line and output load variations and primary to secondary isolation capability [5]- [8]. The power factor correction is done in a single stage approach as well as a two stage approach.

- A single stage approach can use a flyback converter which can perform power factor correction and also voltage regulation

- A two stage approach would use a PFC Boost converter followed by the flyback converter

In a two stage approach a PFC boost converter would take the universal input $\left(85 V_{a c}-265 V_{a c}\right)$ and boost this input to a constant $400 \mathrm{~V}$ DC. This $400 \mathrm{~V} \mathrm{DC}$ is stepped down by second stage which can be a flyback or an LLC resonant converter. Secondary stage flyback is simple to design and leads to a lower bill of materials (BOM), cost and lower efficiency compared to LLC resonant converter. LLC resonant converter is a resonant topology which can give higher efficiency compared to a hard switched topology by providing Zero Voltage Switching (ZVS) to the primary half bridge MOSFET switches. It also provides zero voltage and Zero Current Switching (ZCS) to the secondary side synchronous rectifier MOSFETs. The downside of LLC resonant converter is its complex design methodology, higher component count and bill of materials cost.

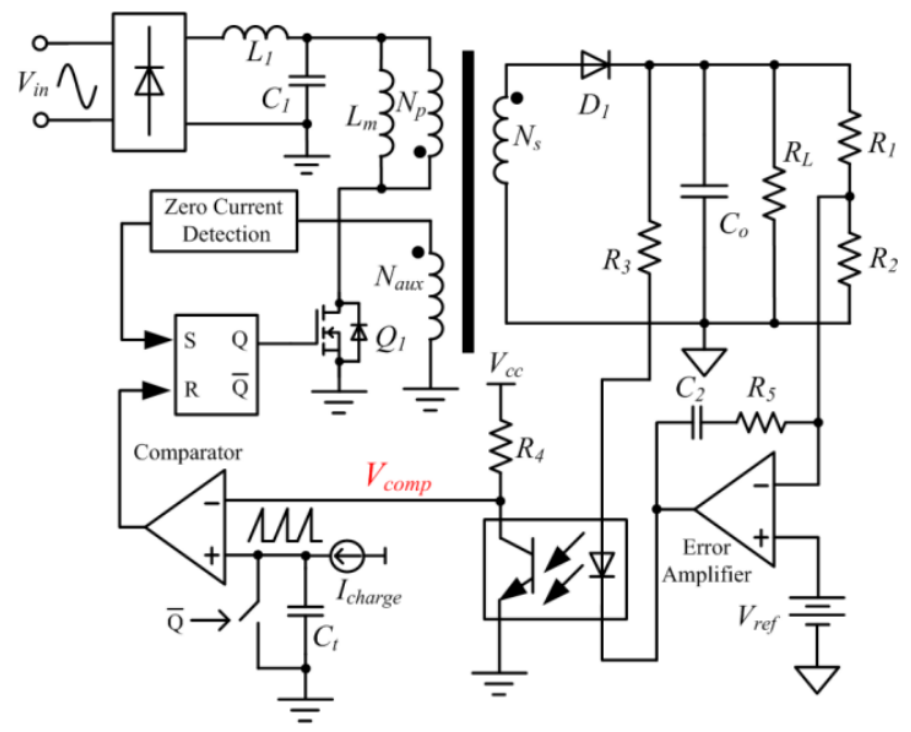

Fig. 1. Boundary mode flyback converter [5]

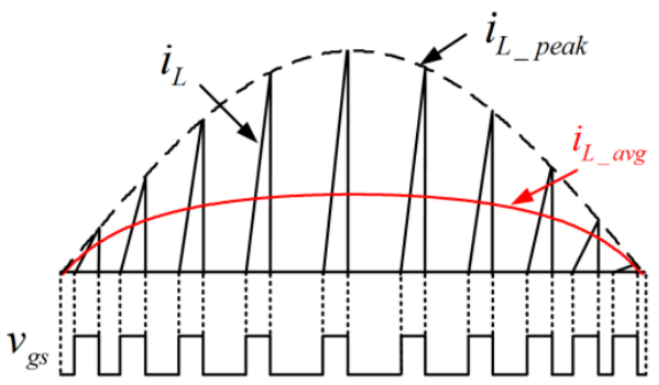

Fig. 2. Theoretical transformer peak and average currents [5]

In [9], the authors use a complicated sliding mode controller to implement PFC flyback with the use of extra switches, but do not show a complete design of the converter. Flyback implementation using discontinuous conduction mode (DCM) is shown in [8]. The problem with DCM mode is the peak and the RMS currents are higher compared to critical conduction mode or continuous conduction mode. The implementation of the circuit in [8] tends to be open loop and the efficiency is low due to the losses in the primary MOSFET and secondary side diode. 
In [4], the authors implemented an extra gate drive circuit for the secondary side synchronous MOSFET which increases the component count and the complexity of the gate drive circuitry. In addition to this, the power factor goes below 0.8 at the line voltage of $150 V_{a c}-230 V_{a c}$ and the power rating is only $75 \mathrm{~W}$. In [10], the authors implement a variable ON time technique for an input AC cycle by introducing a complex multiplier circuit at the output of an optocoupler which needs extra gate pulses for the MOSFETs. The results show crossover distortion at the input $\mathrm{AC}$ cycle zero crossing which increased the total harmonic distortion.

The power levels of the converter in [11] shows a complicated two stage approach which uses a forward and flyback to achieve power factor correction. This method shows higher voltage stress on forward MOSFET which is approximately two times the input voltage plus the extra leakage spikes, this has lead to loss in efficiency. In [15] and [17], the authors discuss about primary side regulated flyback which becomes difficult to implement at $100 \mathrm{~W}$, especially if the regulation is through auxiliary winding. In [16], authors use LLC half bridge resonant converter which is suitable for $100 \mathrm{~W}$ design, but the disadvantages include higher BOM cost and increased complexity.

In this paper, a $100 \mathrm{~W}$ single stage PFC flyback is introduced. In Section II, the complete operation of the flyback is explained. Section III briefly reviews the major equations required to design the $100 \mathrm{~W}$ single stage flyback converter running from a universal AC voltage of $85 V_{a c}-265 V_{a c}$. Section IV shows the results and waveforms of the complete design.

\section{Constant Voltage PFC Flyback}

\section{A. Operation of the Power Factor Correction (PFC) flyback:}

In Fig. 11 the basic diagram of a single stage flyback converter is shown. When the primary MOSFET turns ON, the current in the transformer primary ramps up as shown in Fig. 2 During the primary MOSFET ON time, the voltage across the primary magnetizing inductance is equal to the input voltage. When primary MOSFET is ON, the secondary side diode or synchronous MOSFET remains OFF due to the direction of dot winding.

The secondary diode sees a voltage of $-N V_{i n}$ at the anode and at the cathode a voltage $V_{\text {out }}$ where $\mathrm{N}$ is the turns ratio. Since the current does not circulate on the primary and secondary at the same time, the flyback transformer is called a coupled inductor [12]. When the flyback PWM IC turns the primary MOSFET off, the voltage across the primary inductor reverses in an attempt to keep the ampere turns constant. The voltage across the primary MOSFET is the sum of input voltage $V_{i n}$ and the voltage across the primary inductance $V_{L p}$. The secondary side diode has a positive voltage developed across it and starts conducting. The energy stored in the inductance is transferred to the secondary side thereby charging the output capacitor.

During the duration when secondary diode is $\mathrm{ON}$, the output voltage flies back to the primary and becomes $\frac{V_{o u t}}{N}$ [12]. Hence the name flyback. In boundary mode flyback, the PWM IC IRS2982 turns ON the primary MOSFET for a constant amount of time. Therefore the current ramps up during $\mathrm{ON}$ time and ramps down during OFF time based on the voltage applied across the primary inductor during $\mathrm{ON}$ time which is $V_{i n}$, and during OFF time - $\frac{V_{O U T}}{N}$. In this way, the average input current automatically follows the input rectified AC line voltage as shown in Fig. 2

IRS2982 PWM IC eliminates the usage of conventional extra multiplier circuit used from the DC bus since it uses the concept of constant ON time.The OFF time is detected using an extra auxiliary winding used in the transformer which detects the zero crossing of the inductor current and gives a command to turn ON the primary MOSFET thereby starting a new switching cycle [1], [12]. The frequency in boundary mode is not fixed and it is variable. The ON time is fixed and the off time is variable. At low input AC voltage, the operating frequency is lower since the duty ratio is higher whereas at higher input voltage, the duty ratio is lower and the operating frequency is higher.

Flyback converter operating in boundary mode or critical conduction mode has several advantages such as the power stage of the complete converter appears as a first order system, the reverse recovery of the secondary side diode does not pose problems and the primary inductance value is low. The secondary side diode need not be a fast recovery diode. The limit on using boundary mode is roughly around $200 \mathrm{~W}-250$ $\mathrm{W}$. The reason being the peak and RMS currents increase as the power levels go up which translate to higher power losses in the MOSFET and higher losses in the transformer due to higher AC flux swing [13].

In order to regulate the output voltage, the regulation occurs via a low-bandwidth closed-loop system, which in voltage mode control maintains a constant on time to ensure a unity power factor operation. In current mode, the controller imposes a sinusoidal peak inductor current, without actively tracking the average value of this current [13].

\section{B. Synchronous MOSFET rectifier:}

In order to improve the efficiency of the flyback converter, on the secondary a synchronous MOSFET rectifier is used. When the secondary side conducts, the current starts flowing through the body diode of the secondary MOSFET, the voltage across the MOSFET is sensed by the IR1161L IC and it turns ON the MOSFET, thereby reducing the losses significantly from $V_{f} \cdot I_{O U T}$ to $R_{d s o n} \cdot I_{O U T}^{2}$.

\section{FlybaCk CONVERTER DESIGN}

In this paper a $100 \mathrm{~W}$ PFC flyback design, on the secondary side a TL431 is used which has an internal $2.5 \mathrm{~V}$ reference (Fig. 11). When the output voltage goes higher than $2.5 \mathrm{~V}$, the TL431 starts sinking current, thereby modulating the current in the optocoupler diode which turns ON the internal BJT transistor. The collector of this BJT transistor is connected to the COMP pin of the IC IRS2982. Once the BJT turns ON, the COMP is pulled low, thereby limiting the duty cycle. The COMP pin decides the ON time of the primary MOSFET. If the COMP voltage is high then the duty cycle will be longer (primary MOSFET is ON for a longer duration) which translates to more energy being transferred to the secondary 
side and vice versa. In Table I, different parameters have been shown related to the $100 \mathrm{~W}$ PFC flyback board design.

TABLE I. PARAMETERS OF THE PFC FLyBACK

\begin{tabular}{ll}
\hline Parameters & Value \\
\hline AC Input Voltage Range $\left(V_{a c}\right)$ & $85-264 \mathrm{~V}$ \\
\hline Output Voltage $\left(V_{o}\right)$ & $24 \mathrm{~V}$ \\
\hline Output Current $\left(I_{o}\right)$ & $4.2 \mathrm{~A}$ \\
\hline Input Line Frequency $(H z)$ & $60 \mathrm{~Hz}$ \\
\hline Minimum Frequency $\left(f_{M I N}\right)$ & $70 \mathrm{kHz}$ \\
\hline Transformer Core & EER35 \\
\hline Primary Inductance $\left(L_{P}\right)$ & $160 \mu \mathrm{H}$ \\
\hline Primary Mosfet $\left(M_{2}\right)$ & IPD80R360P7S \\
\hline Secondary Synchronous Mosfet $\left(M_{1}\right)$ & IPB073N15N5 \\
\hline Primary PWM Controller $\left(I C_{1}\right)$ & IRS2982S \\
\hline Secondary Synchronous Controller $\left(U_{1}\right)$ & IR1161L \\
\hline Output Capacitor $\left(C_{o}\right)$ & $1410 \mu \mathrm{F}$ \\
\hline Maximum Duty Cycle $\left(D_{m a x}\right)$ & 0.5 \\
\hline Turns $\left(N_{p}: N_{s}: N_{a u x}: N_{s_{2}}\right)$ & $40: 6: 5: 3$ \\
\hline Minimum Input Voltage $\left(V_{a c_{m i n}}\right)$ & $85 \mathrm{~V}$ \\
\hline Output ripple $\left(V_{r i p p l e}\right)$ & $2 \mathrm{~V}$ \\
\hline Leakage Inductance & $3.75 \mu \mathrm{H}$ \\
\hline Turns ratio $\left(n=\frac{N_{s}}{N_{p}}\right)$ & 0.15 \\
\hline Peak Primary Current $\left(I_{p e a k}\right)$ & 4.54 \\
\hline
\end{tabular}

\section{Design Equations:}

Transformer inductance is determined (1) [4], [17]:

$$
L_{\text {pri }}=\frac{V_{\text {acmin }}^{2} \eta D_{\max }^{2}}{\sqrt{2} P_{\text {outmax }} f_{\min }}
$$

- $\quad L_{p r i}$ is the primary inductance

- $V_{\text {acmin }}$ is the minimum AC voltage

- $D_{\max }$ is the maximum duty cycle

- $\quad P_{\text {outmax }}$ is the maximum output power

- $f_{\min }$ is the minimum frequency

Turns ratio of the transformer is given by (2)

$$
\frac{N_{S}}{N_{P}}=\frac{V_{o u t}+V_{f}}{\sqrt{2} V_{\text {acmin }}} \cdot \frac{1-D_{\max }}{D_{\max }}
$$

- $\quad N_{s}$ is the secondary winding turns

- $N_{p}$ is the primary number of turns

- $V_{f}$ is the forward drop of the diode

Auxiliary to primary turns ratio is given by (3) and auxiliary to secondary turns ratio is given by (4)

$$
\begin{aligned}
& \frac{N_{A}}{N_{P}}=\frac{V_{\text {auxmax }}+V_{f}}{\sqrt{2} V_{\text {acmin }}} \cdot \frac{1-D_{\max }}{D_{\max }} \\
& \frac{N_{A}}{N_{S}}=\frac{V_{\text {auxmax }}+V_{f}}{V_{\text {out }}+V_{f}}
\end{aligned}
$$

- $\quad N_{A}$ is the number of auxiliary winding
In a single stage flyback, the $120 \mathrm{~Hz}$ ripple is quite large compared to a two-stage topology. The higher the number of output capacitors, the lower is the output low frequency 120 $\mathrm{Hz}$ ripple. The output capacitance is calculated using the below formula:

$$
C_{O}=\frac{I_{\text {out }}}{2 \cdot \pi \cdot f_{\text {acmin }} \cdot V_{\text {ripple }}}
$$

- $C_{o}$ is the output capacitance

- $I_{\text {out }}$ is the output current,

- $f_{\text {acmin }}$ is the minimum input $\mathrm{AC}$ line frequency

- $V_{\text {ripple }}$ is the acceptable ripple on the output voltage

From the schematic shown in Fig. 11, the output capacitance used is around $1410 \mu \mathrm{F}$. The higher the capacitance, the lower is the $120 \mathrm{~Hz}$ ripple. The leakage in a flyback transformer can be an issue for the operation of the primary MOSFET. When the primary MOSFET in the converter turns OFF, the leakage inductance of the transformer rings with the $C_{o s s}$ of the MOSFET. The leakage spike plus the input voltage appears across the MOSFET. If the leakage spike is not clamped or limited to a safe voltage lower than the breakdown voltage of the MOSFET, then the MOSFET could easily be destroyed. In order to limit the leakage spike, an RCD snubber is used [14]. The equations of the RC snubber are shown in (6).

$$
R_{S}=\frac{V_{s n}^{2}}{\frac{1}{2} \cdot L_{l k} \cdot I_{\text {peak }}^{2}\left(\frac{V_{s n}}{V_{s n}-n \cdot V_{0}}\right) f_{S}}
$$

- $V_{s n}$ is the clamp voltage

- $L_{l k}$ is the leakage inductance

- $\mathrm{n}$ is the turns ratio

- $I_{\text {peak }}$ is the peak primary transformer current

Snubber capacitor is given by (7)

$$
C_{S n}=\frac{V_{s n}}{\Delta V_{s n} R_{s n} f_{s}}
$$

- $C_{s n}$ is the snubber capacitor

- $R_{s n}$ is the snubber resistor

From Fig. 11 the snubber capacitor is a $2.2 \mathrm{nF} / 630 \mathrm{~V}$ and snubber resistor is a $2 \mathrm{~W} / 75 \mathrm{k} \Omega$

TABLE II. RESULTS AT 120 VAC

\begin{tabular}{c|c|c|c|c|c|c}
$\begin{array}{c}P_{I N} \\
(\mathrm{~W})\end{array}$ & $\begin{array}{c}V_{\text {OUT }} \\
(\mathrm{V})\end{array}$ & $\begin{array}{c}I_{\text {OUT }} \\
(\mathrm{A})\end{array}$ & $\begin{array}{c}P_{\text {OUT }} \\
(\mathrm{W})\end{array}$ & $\mathrm{PF}$ & $\begin{array}{c}I_{T H D} \\
(\%)\end{array}$ & $\begin{array}{c}\eta \\
(\%)\end{array}$ \\
\hline 114.68 & 23.96 & 4.20 & 100.8 & 0.99 & 6 & 87.90 \\
\hline 109.07 & 23.96 & 4.00 & 95.98 & 0.99 & 6.4 & 88.00 \\
\hline 102.09 & 23.96 & 3.75 & 89.99 & 0.99 & 4.9 & 88.15 \\
\hline 95.18 & 23.96 & 3.50 & 84.00 & 0.99 & 6.35 & 88.26 \\
\hline 88.15 & 23.96 & 3.25 & 78.01 & 0.99 & 4.45 & 88.50 \\
\hline 81.4 & 23.96 & 3.00 & 72.05 & 0.99 & 6.26 & 88.51 \\
\hline 74.63 & 23.96 & 2.75 & 66.03 & 0.99 & 6.2 & 88.48 \\
\hline 67.92 & 23.96 & 2.50 & 60.04 & 0.99 & 4 & 88.40 \\
\hline 54.52 & 23.96 & 2.00 & 48.06 & 0.99 & 7.95 & 88.16 \\
\hline 41.65 & 23.96 & 1.50 & 36.08 & 0.99 & 9.61 & 86.64 \\
\hline 28.86 & 23.97 & 1.00 & 24.09 & 0.99 & 10.53 & 83.47 \\
\hline 16.54 & 23.97 & 0.51 & 12.22 & 0.94 & 27.23 & 73.87 \\
\hline 9.26 & 23.97 & 0.27 & 6.52 & 0.90 & 32.46 & 67.74
\end{tabular}




\section{EXPERIMENTAL RESULTS}

Table II lists the power factor, THD, efficiency, and output voltage regulation at various loads starting from no load to a full load of $100 \mathrm{~W}$ at $120 \mathrm{~V}$ input $\mathrm{AC}$ line voltage. As it can be seen from the table, the output voltage regulation over the load is constant. It can also be observed that the power factor is greater than 0.9 and THD is less than $11 \%$ from $25 \%$ load to $100 \%$ load.

Table III shows the results at $230 \mathrm{~V}$ AC input line voltage. The output voltage regulation is stable. Power factor is greater than 0.9 and THD is less than $20 \%$ from $25 \%$ load to $100 \%$ load. The efficiency of flyback converter is well within acceptable limits.

Figs. 3 and 4 show that the complete $100 \mathrm{~W}$ design met the IEC61000 standard. Figure 5 shows the steady state waveforms of converter at $120 \mathrm{Vac}$ and figure 7 show the waveforms at 230 Vac. The AC ripple on the output voltage can be reduced by adding extra capacitors. Fig. 6 shows the start-up of the converter. As it can be seen there is no overshoot on the output voltage at the start up. The Figs. 8 and 9 show the steady state waveforms of the designed converter. Figs. 11 and 12 show the complete schematic of the flyback converter. From figures 13 and 14, it is clear that the flyback converter is very stable as phase margin is 40 degrees at 120 VAC and 54 degrees at 230 VAC.

Figure 10 illustrates the $V_{D S}$ and $V_{G S}$ waveforms of secondary side MOSFET at 230 VAC. When drain current on the secondary flows through the body diode of the secondary MOSFET, the synchronous IC IR1161L uses the $V_{D S}$ sensing method to detect the negative $V_{D S}$ ( greater than $-0.23 \mathrm{~V}$ ) and turns ON the MOSFET gate to reduce the power losses in the diode. When the secondary current reaches close to zero, the IR1161L detects the $V_{D S}$ voltage and when it is in the range $-8 \mathrm{mV}$ to $-4 \mathrm{mV}$, it turns off the MOSFET gate. In this design, instead of using a simple diode on the secondary side, the design uses a MOSFET in order to reduce the power losses in the diode from $V_{f} \cdot I_{\text {out }}$ to $I_{d s}^{2} \cdot R_{d s o n}$. By doing this, the heat sink requirement on the secondary side is eliminated by making use of a synchronous MOSFET.

TABLE III. RESUlTS AT 230 VAC

\begin{tabular}{c|c|c|c|c|c|c}
$\begin{array}{c}P_{I N} \\
(\mathrm{~W})\end{array}$ & $\begin{array}{c}V_{\text {OUT }} \\
(\mathrm{V})\end{array}$ & $\begin{array}{c}I_{\text {OUT }} \\
(\mathrm{A})\end{array}$ & $\begin{array}{c}P_{\text {OUT }} \\
(\mathrm{W})\end{array}$ & $\mathrm{PF}$ & $\begin{array}{c}I_{T H D} \\
(\%)\end{array}$ & $\begin{array}{c}\eta \\
(\%)\end{array}$ \\
\hline 111.76 & 23.97 & 4.212 & 100.96 & 0.988 & 9.43 & 90.34 \\
\hline 106.58 & 23.97 & 4.011 & 96.14 & 0.987 & 10.18 & 90.21 \\
\hline 100.11 & 23.97 & 3.761 & 90.15 & 0.986 & 11.11 & 90.05 \\
\hline 93.63 & 23.97 & 3.514 & 84.23 & 0.984 & 11.41 & 89.96 \\
\hline 87.35 & 23.97 & 3.264 & 78.24 & 0.981 & 12.58 & 89.57 \\
\hline 80.97 & 23.97 & 3.013 & 72.22 & 0.978 & 13 & 89.20 \\
\hline 74.63 & 23.97 & 2.763 & 66.23 & 0.975 & 12.21 & 88.74 \\
\hline 68.41 & 23.97 & 2.515 & 60.28 & 0.971 & 13.11 & 88.12 \\
\hline 55.75 & 23.97 & 2.013 & 48.25 & 0.952 & 13.49 & 86.55 \\
\hline 43.27 & 23.97 & 1.518 & 36.39 & 0.935 & 15.88 & 84.09 \\
\hline 31.28 & 23.97 & 1.015 & 24.33 & 0.891 & 19.62 & 77.78 \\
\hline 16.69 & 23.97 & 0.509 & 12.20 & 0.749 & 24.9 & 73.08 \\
\hline 10.192 & 23.97 & 0.261 & 6.26 & 0.581 & 37.82 & 61.38
\end{tabular}

\section{Conclusion}

In this paper a $100 \mathrm{~W}$ single stage PFC flyback design was presented. The results show that a single stage PFC flyback can be pushed to a higher power level thereby reducing

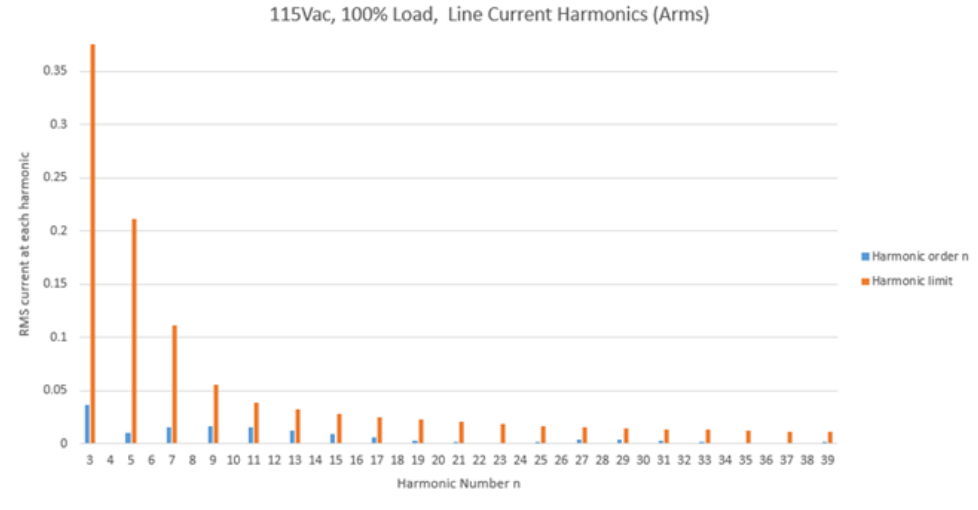

Fig. 3. IEC61000-3-2 Class D harmonic limits met at $120 \mathrm{Vac}$

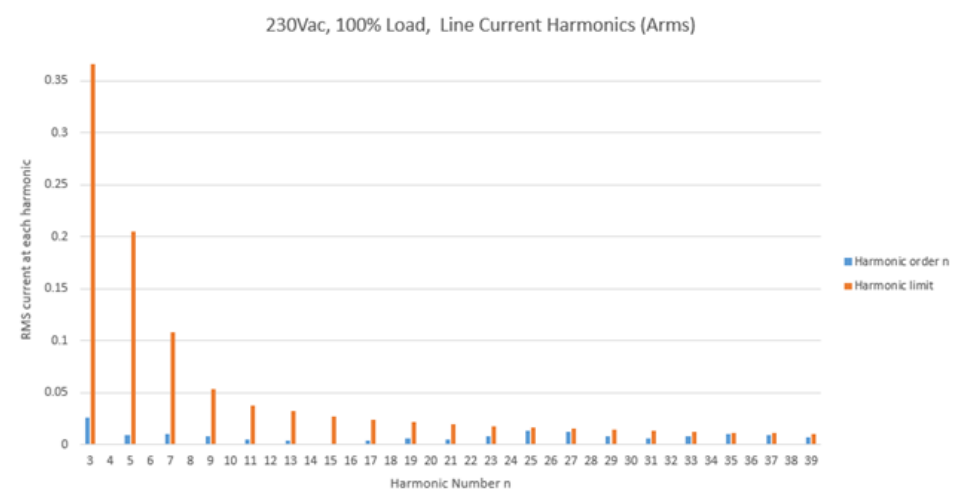

Fig. 4. IEC61000-3-2 Class D harmonic limits met at $230 \mathrm{Vac}$

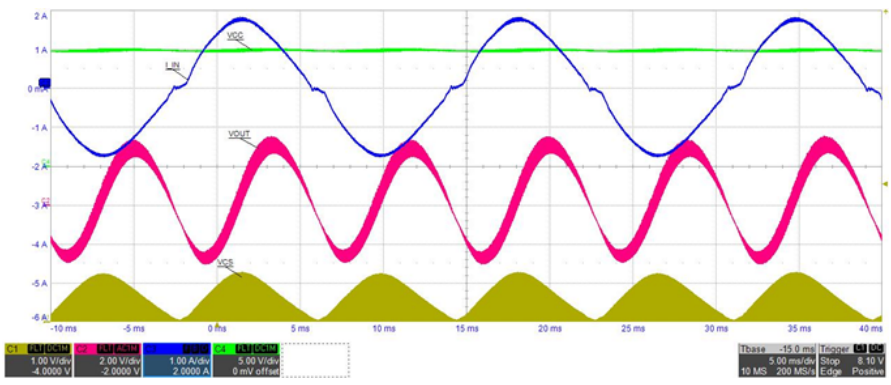

Fig. 5. Steady state waveforms at 120 Vac: Input current (Blue), Current sense voltage (Yellow), Vout ripple (Red), Vcc (Green)

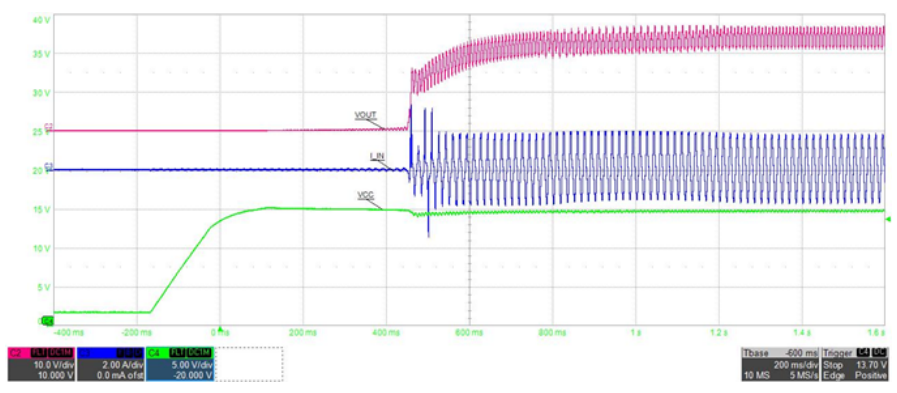

Fig. 6. Startup at 120 Vac : Vout (Red), Input current (Blue), Vcc ( Green)

the component count while maintaining a higher level of efficiency. The Power factor over the input voltage range was greater than 0.9 and THD remained less than $20 \%$. 


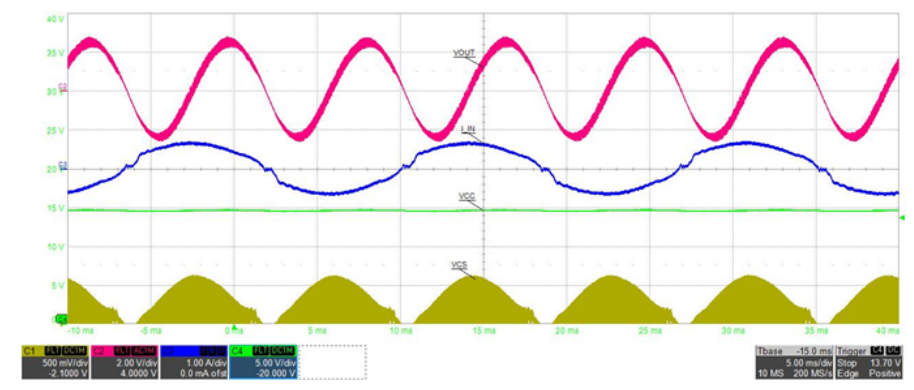

Fig. 7. Steady state waveforms at 230 Vac: Input current (Blue), Current sense voltage (Yellow), Vout ripple (Red), Vcc (Green)

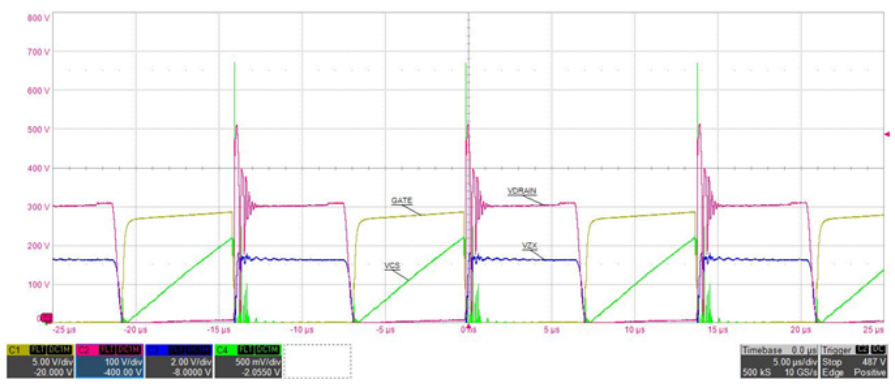

Fig. 8. Steady state waveforms at 120 Vac: MOSFET drain voltage (Red), Current sense voltage (VCS:Green), MOSFET gate (Yellow), Zero crossing voltage at the auxiliary winding (VZX : Blue)

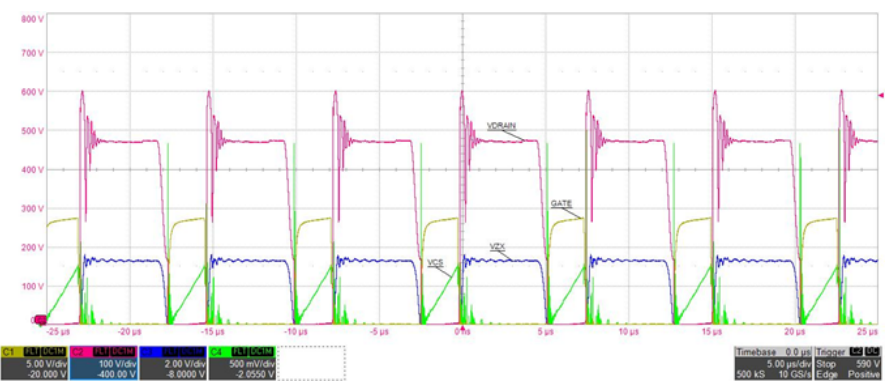

Fig. 9. Waveforms at 230 Vac: Drain voltage (Red), Current sense voltage (VCS: Green), Gate (Yellow), Zero crossing voltage (VZX : Blue)

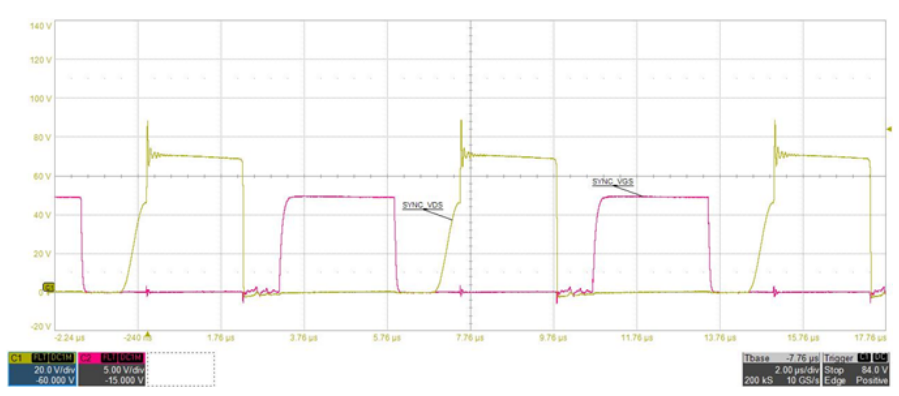

Fig. 10. Synchronous rectification MOSFET waveforms at 230Vac, Drain voltage of the synchronous MOSFET (Vds: Yellow), Gate of the MOSFET (Vgs: Red)

\section{REFERENCES}

[1] K. N. Sakthivel, S. K. Das, and K. R. Kini, "Importance of quality AC power distribution and understanding of EMC standards IEC 61000-3-2, IEC 61000-3-3 and IEC 61000-3-11," in Proc. of the Electromagnetic Interference \& Compatibility, 2003, vol. 8, pp. 423-430.

[2] Electromagnetic compatibility (EMC)-Part 3-2: Limits-limits for har-

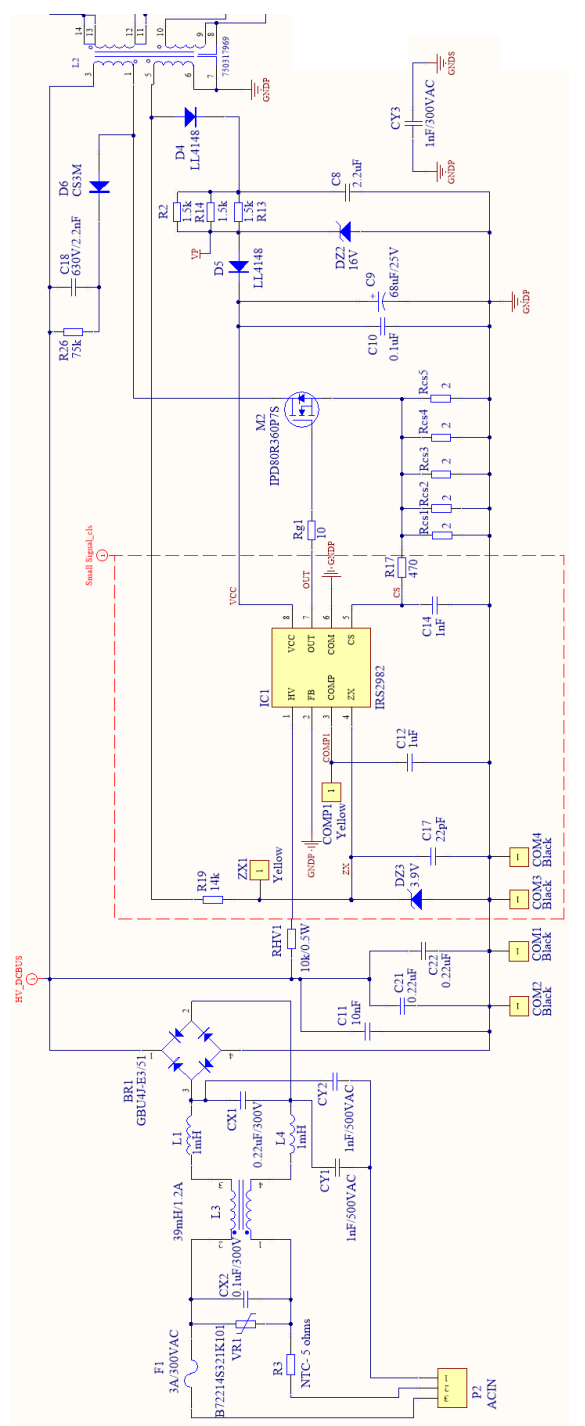

Fig. 11. Complete schematic of $100 \mathrm{~W}$ single stage PFC Flyback

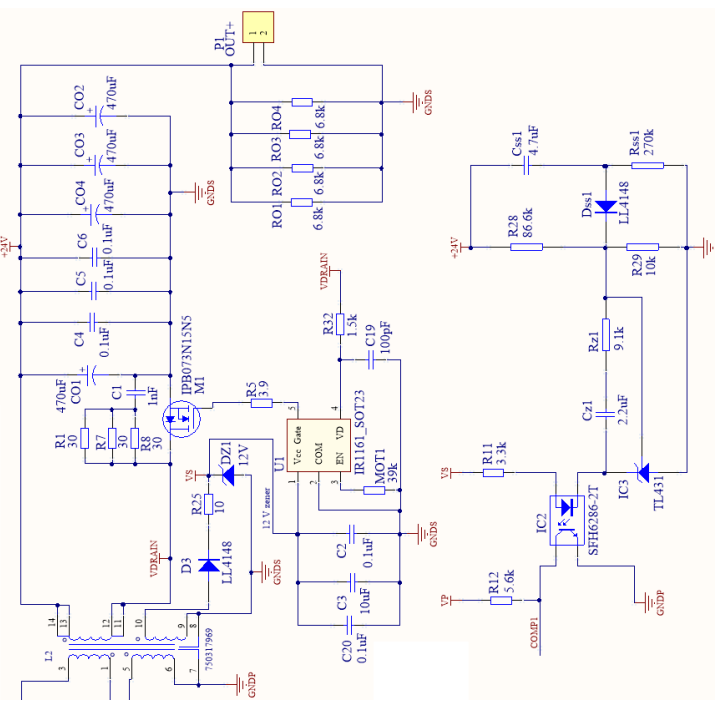

Fig. 12. Secondary side of $100 \mathrm{~W}$ single stage PFC Flyback 


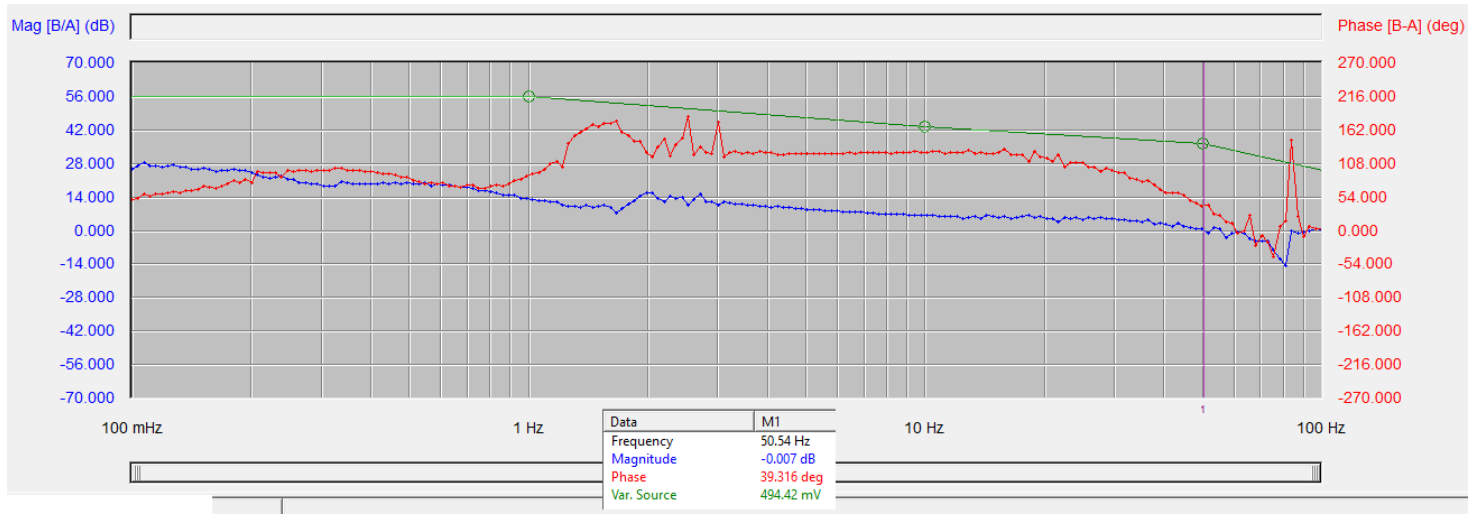

Fig. 13. Phase Margin of the converter is $40 \mathrm{Deg}$ at 120 VAC

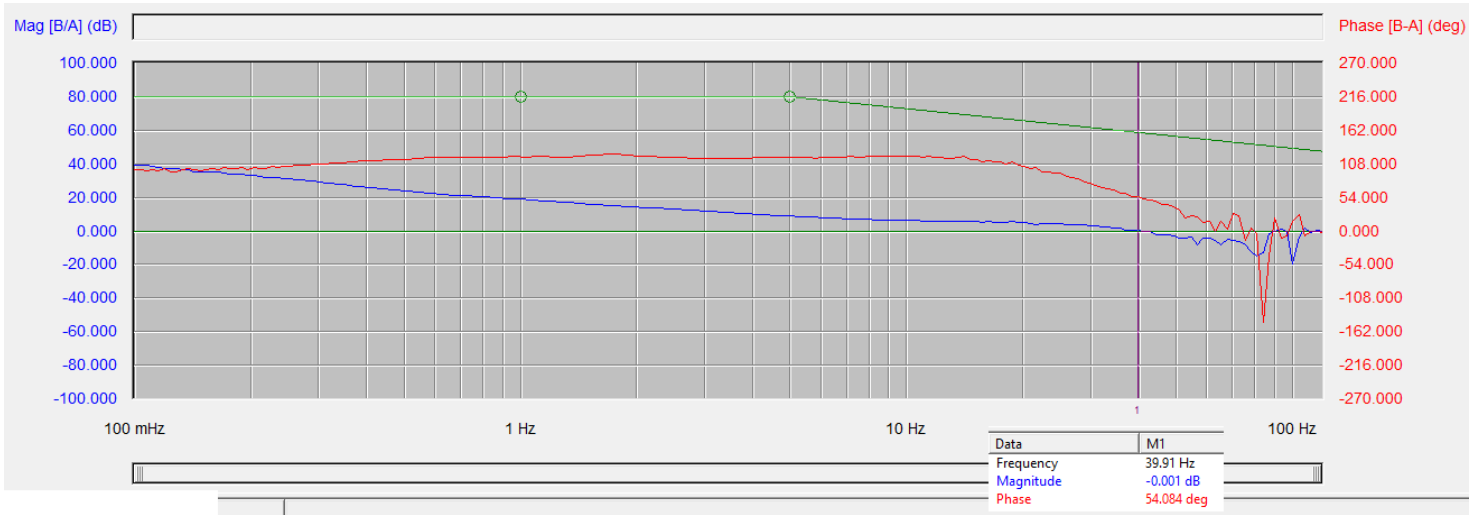

Fig. 14. Phase Margin of the converter is 54 Deg at 230 VAC

monic current emissions (equipment input current $\leq 16$ A per phase), Edition 2.2, IEC 61000-3-2, Nov. 2004.

[3] Technical Requirements Table, V4.0, DesignLights Consortium, 2016.

[4] Y.-K. Lo, J.-Y. Lin, and S.-Y. Ou, "Single-Stage Single-Switch PFC Flyback Converter Using a Synchronous Rectifier," in Proc. IEEE Trans. Ind. Electron., vol. 55, no. 3, Mar. 2008.

[5] C. Zhao, and J. Zhang, "An Improved Variable On-Time Control Strategy for a CRM Flyback PFC Converter," in Proc. IEEE Trans. Power Electron., 2017, vol. 32.

[6] K.-W. Siu and Y.-S. Lee, "A novel high-efficiency flyback power-factor correction circuit with regenerative clamping and soft switching," IEEE Trans. Circuit Syst. I, Fundam. Theory Appl., vol. 47, no. 3, pp. 350356, Mar. 2000

[7] J. Zhang, H. Zeng, and T. Jiang, "A primary-side control scheme for high power-factor LED driver with TRIAC dimming capability," IEEE Trans. Power Electron., vol. 27, no. 11, pp. 4619-4629, Nov. 2012.

[8] R. Erickson, M. Madigan, S. Singer, "Design of a simple high-powerfactor rectifier based on the flyback converter", Proc. of the Applied Power Electronics Conference and Exposition (APEC '90), pp. 792 801, 1990

[9] V. Fernao , J. Martins, and J. Fernando Silva, "A Single Stage Flyback PFC Converter for Testing Distance Relay Systems", 7th International Conference on Power Electronics and Drive Systems, 2007

[10] T. Yan, J. Xu, F. Zhang, J. Sha, and Z. Dong, "Variable-on-timecontrolled critical-conduction-mode flyback PFC converter," IEEE Trans. Ind. Electron., vol. 61, no. 11, pp. 6091-6099, Nov. 2014

[11] T. Xie, J. Li, K. Peng, C. Zhao, and Q. Lu, "Study on the Single-stage Forward-flyback PFC Converter with QR Control," in Proc. IEEE Trans. Power Electron., vol. 31, Issue 1, 2016.

[12] Christophe Basso, "Switch-Mode Power Supplies Spice Simulations and Practical Designs" McGraw-Hill Professional; 1st edition, Feb 4, 2008.
[13] Peter Green, "55 W Flyback converter design using the IRS2982S controller", Infineon Technologies.

[14] A. Hren, J. Korelic, and M. Milanovic, "RC-RCD Clamp Circuit for Ringing Losses Reduction in a Flyback Converter," in Proc. IEEE Trans. Circuits and Systems, vol. 53, No. 5, May 2006.

[15] Kali Naraharisetti, "Primary side regulated flyback AC-DC converter for LED's," 2015 IEEE EIT Conference, Illinois, USA.

[16] Kali Naraharisetti, "Design of half bridge LLC resonant converter using synchronous rectifier," 2015 IEEE EIT Conference, Illinois, USA.

[17] Kali Naraharisetti, Peter B. Green, "How to design a flyback converter as a front-end for a two-stage LED driver," EDN Magazine. 